\title{
Occupational asthma caused by stainless steel welding fumes: a clinical study
}

\author{
T. Hannu, R. Piipari, M. Tuppurainen, H. Nordman and T. Tuomi
}

ABSTRACT: The aim of the present study was to describe the cases of occupational asthma (OA) due to stainless steel welding fumes diagnosed at the Finnish Institute of Occupational Health during the period 1994-2003.

OA was diagnosed according to patient history, lung function examinations and welding challenge tests with measurements of the forced expiratory volume in one second (FEV 1$)$ and peak expiratory flow (PEF) values.

The present series comprised 34 patients, all male, with a mean age of 44.7 yrs (range 22-57), mainly working as welders. The mean duration of exposure was 22.4 yrs, and the mean duration of exposure before the onset of respiratory symptoms was 18 yrs. Dyspnoea was the most frequently reported work-related respiratory symptom. During the inhalation challenge tests, the mode of the asthmatic FEV 1 /PEF reaction was delayed in $16(47 \%)$ patients, immediate in nine (26\%) patients and dual (both immediate and delayed) in nine (26\%) patients. In the follow-up assessment 6 months later, only six patients were considered able to continue performing welding tasks, whereas occupational injury pension was recommended for seven, and measures of vocational rehabilitation for 14 patients.

In most cases, after the diagnosis of occupational asthma, the continuation of welding work was not possible.

KEYWORDS: Challenge test, occupational asthma, stainless steel, welding

W elding refers to any process of joining pieces of metal at joint faces that have been made soft or liquid by heat. Welders are exposed to fumes containing different gases and particles, depending on the composition of the welding electrodes, welded material and the welding method used. In Finland, it is estimated that $\sim 13,000$ workers work as full-time welders, while the corresponding number in the USA is $>400,000$ [1]. Health effects associated with welding include chronic bronchitis, metal fume fever, lung function abnormalities and asthma [1, 2].

Several case reports have revealed occupational asthma (OA) in workers welding on common stainless steel [3, 4], special stainless steels [5] and painted steel [6], as well as aluminium [7]. According to recent population-based studies, welders run an almost two-fold risk of developing asthma [8, 9]. Moreover, some epidemiological studies have indicated that exposure to welding fumes may indeed be a direct cause of asthma [10-12].

Thus far, patient series dealing with welding challenge test-positive cases of OA are sparse [3, 4], reflecting the fact that these tests are not performed routinely. To date, no analyses of large patient series from clinics of occupational medicine or pulmonology have been published.

In the present paper, a patient series consisting of 34 welders with OA diagnosed with positive stainless steel welding challenge tests is described.

\section{METHODS}

\section{Patients}

The present study comprises the cases (i.e. a subject with OA with positive stainless steel welding challenge test) diagnosed at the Finnish Institute of Occupational Health (FIOH; Helsinki, Finland) during the years 1994-2003. The patients were referred to the FIOH by pulmonologists at local central hospitals or by physicians at local occupational health units from all over Finland. The ethics committee of the $\mathrm{FIOH}$ approved the study. Primary investigations at the $\mathrm{FIOH}$ included allergological and lung function examinations with specific inhalation challenge tests. All the patients except one (the patient had retired before the examinations) with diagnosed OA were called to the FIOH for a follow-up
AFFILIATION

Finnish Institute of Occupational Health, Occupational Medicine, Helsinki, Finland.

CORRESPONDENCE

T. Hannu

Finnish Institute of Occupational Health

Topeliuksenkatu 41 a A Fl-02500 Helsinki

Finland

Fax: 358304742149

E-mail: timo.hannu@ttl.fi

Received:

May 012006

Accepted after revision:

August 132006 
examination, including lung function examinations, 6 months after the diagnosis. The purpose of this follow-up examination was to check the stability of asthma and the status of the measurements of vocational rehabilitation.

\section{Allergological examinations}

Skin-prick tests (SPT) for common environmental allergens (ALK-Abello A/S, Copenhagen, Denmark), as well as for metal salts (hexavalent and trivalent chromium, nickel and cobalt), were performed as reported previously [13]. Histamine hydrochloride $\left(10 \mathrm{mg} \cdot \mathrm{mL}^{-1}\right)$ was used as the positive control. The environmental allergens were the following: pollens of birch, alder, timothy hay, meadow foxtail, mugwort and dandelion; epithelia of horse, dog, cat and cow; dust mites (Dermatophagoides farinae, Dermatophagoides pteronyssinus); and moulds (Alternaria alternata, Cladosporium herbarum). The concentrations of the metals tested for in water solutions were as follows: nickel sulphate $10 \mathrm{mg} \mathrm{NiSO} \cdot \mathrm{mL}^{-1}$, potassium

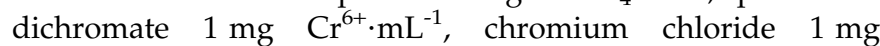
$\mathrm{Cr}^{3+} \cdot \mathrm{mL}^{-1}$ and cobalt chloride $1 \mathrm{mg} \mathrm{Co}{ }^{2+} \cdot \mathrm{mL}^{-1}$. A positive reaction was defined as a weal diameter $\geqslant 3 \mathrm{~mm}$ in the absence of reaction to the diluent and in the presence of a positive reaction to histamine phosphate.

Total immunoglobulin (Ig)E values were determined using the Pharmacia capsulated hydrophilic carrier polymer (CAP) system IgE radioimmunoassay (Kabi Pharmacia Diagnostics, Uppsala, Sweden) until 1996. After that date, IgE values were measured using the Uni-CAP system (Pharmacia \& Upjohn, Uppsala, Sweden).

Atopy was defined either as a positive result to any common environmental allergens (one or more allergens) in SPT, or as positive atopic history (earlier infantile eczema, atopic dermatitis, or hay fever or other allergic rhinitis).

\section{Lung function examinations}

Flow-volume spirometry was performed with a pneumotachograph spirometer connected to a microcomputer (Medicro MR909; Medikro, Kuopio, Finland) using the reference values of VILJANEN [14]. Three spirograms were taken at each measurement. Spirometry was performed according to European Respiratory Society guidelines [15], and forced vital capacity (FVC), forced expiratory volume in one second (FEV1) and the FEV1/FVC ratio (FEV\%) were measured. Spirometry values were graded as follows: normal (FEV1 $>80 \%$, FVC $>81 \%$ and $\mathrm{FEV} \%>87 \%$ of normal value); mild deterioration (FEV1 $65-80 \%$ and/or FVC $65-81 \%$ and/or FEV\% $78-87 \%$ of normal value); moderate deterioration (FEV1 45-64\% and/or FVC $45-64 \%$ and/or $\mathrm{FEV} \% 62-77 \%$ of normal value); and strong deterioration (FEV1 $<45 \%$ and/or FVC $<45 \%$ and/or FEV $\%<62 \%$ of normal value). A histamine challenge test was performed according to the method of SovIJÄRVI et al. [16]; the provocative dose of $1.6 \%$ histamine diphosphate causing a $15 \%$ reduction in FEV1 (PD15) was measured. The hyperresponsiveness was graded as strong with PD15 $<0.10 \mathrm{mg}$, moderate with PD15 0.11-0.40 mg, and mild with PD15 0.41$1.6 \mathrm{mg}$. Peak expiratory flow (PEF) monitoring during work days and days off was carried out according to the method of BURGE [17].

\section{Specific inhalation challenge tests}

OA was diagnosed according to European guidelines [18]. Welding challenge tests were performed in every case, in a special welding chamber. The exposure time was $30 \mathrm{~min}$, during which time five rods in the control test (OK 48.00; ESAB $\mathrm{AB}$, Gothenburg, Sweden) and 11 rods in the stainless steel welding test (OK 63.30; ESAB AB) were consumed. Patients were monitored for $24 \mathrm{~h}$ after each challenge. A portable, pocket-sized spirometer (One Flow; STI MEDICAL, SaintRomans, France) recorded the lung function measurements (FEV1, PEF), and a drop of $20 \%$ in PEF or FEV1 was regarded as significant. Clinical symptoms and lung auscultation findings were also recorded. An asthmatic reaction was defined as follows: an immediate reaction causing a drop $\geqslant 20 \%$ in FEV1 or PEF values during the first post-challenge hour; a delayed reaction causing a similar FEV1 or PEF drop after the first post-challenge hour; and a dual reaction as a combination of those mentioned above. If the patient experienced immediate asthmatic symptoms and/or a significant drop in lung function parameters (FEV1, PEF) was recorded, then the challenge test was interrupted. Mild steel welding was used as a control challenge test. In six cases, this was substituted by a lactose powder challenge test, as these patients connected their respiratory symptoms clearly to stainless steel welding, but a placebo test with mild steel welding could not be performed due to instability of the asthma. In two cases, a second specific challenge test was performed with grinding dust of stainless steel from the workplace. If occupational rhinitis or laryngitis was clinically suspected, otorhinolaryngological status was observed by an otorhinolaryngologist both before and $1 \mathrm{~h}$ after the challenge test.

\section{Statistical analysis}

Proportional data were compared with the Chi-squared test or with Fisher's exact test, and the Mann-Whitney U-test or unpaired t-tests were applied in comparisons of continuous variables. Differences at the $5 \%$ level were considered statistically significant.

\section{RESULTS}

The mean age of the patients was 44.7 yrs (range 22-57), and they were all male (table 1). All patients were exposed to stainless steel welding fumes. They consisted of welders $(n=24)$, machine fitters $(n=4)$, plumbers $(n=3)$, metalworkers $(\mathrm{n}=1)$, metalwork teachers $(\mathrm{n}=1)$ and metalworking inspectors $(n=1)$. Of the patients, $11(32 \%)$ were current smokers, $17(50 \%)$ were ex-smokers and six (18\%) had never smoked.

The mean duration of exposure to stainless steel welding fumes before the examinations at the $\mathrm{FIOH}$ was 22.4 yrs (range $4-40$ ). The mean duration of exposure before the onset of respiratory symptoms was 18.0 yrs (range 0.5-34). Dyspnoea was the most frequently reported work-related respiratory symptom (reported in all but one patient), followed by cough and wheezing. Besides respiratory symptoms, 21 (62\%) patients also had nasal or laryngeal symptoms connected to welding fumes, and four patients had ocular symptoms (irritant effects of welding fumes).

Before the investigations at the $\mathrm{FIOH}$, bronchial asthma was diagnosed in $28(82 \%)$ patients and suspected in five patients 
TABLE 1 General characteristics and allergological examinations of study patients

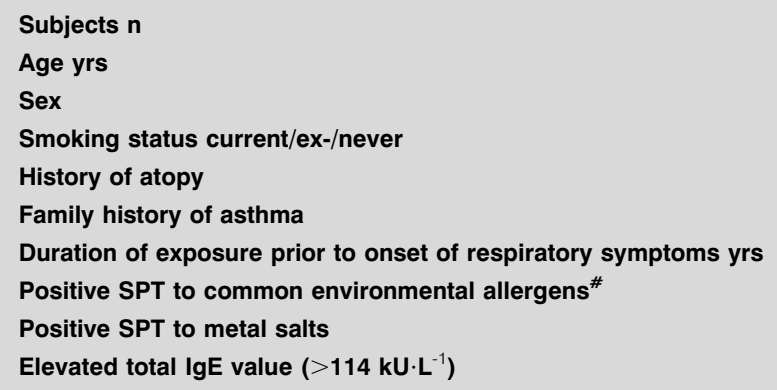

Data are presented as n, mean (range) or positive/tested (\%). SPT: skin prick test; Ig: immunoglobulin. \#: Examined either at the Finnish Institute of Occupational Health (Helsinki, Finland) or at local pulmonology clinics.

during examinations at local pulmonary clinics; one patient had respiratory symptoms related to welding without asthma diagnosis. Regular asthma medication had been started by 24 $(70 \%)$ patients, and a bronchodilating agent on demand had been given to an additional seven (20\%) patients. PEF monitoring during work days and days off was performed locally in only nine $(26 \%)$ patients. PEF measurements were compatible with OA in five cases; in three a proper evaluation was not possible; and in only one case, serial PEF measurements did not fit OA.

Before the examinations at the $\mathrm{FIOH}, 10$ (29\%) patients had positive SPT reactions to common environmental allergens, and in the examinations at the $\mathrm{FIOH}$, nine $(26 \%)$ patients had such reactions; in total, 11 (32\%) patients showed positive SPT reactions to common environmental allergens. At the $\mathrm{FIOH}$, SPT tests to metal salts were performed in $24(70 \%)$ patients, and none showed positive allergic reactions. A total of $13(38 \%)$ patients had an elevated $\left(>114 \mathrm{kU} \cdot \mathrm{L}^{-1}\right)$ total $\mathrm{IgE}$ concentration (range 118-490).

At the FIOH, spirometry was normal or showed only mild obstruction in most patients (table 2). Likewise, most of the patients tested showed no or only mild bronchial hyperresponsiveness in the histamine provocation test. In all patients, the control welding challenge test was negative.

All 34 patients underwent a stainless steel welding challenge test. In seven patients, the challenge tests were performed with inhaled corticosteroid medication due to the instability of their asthma. The ranges of FEV1 or PEF value reductions during the challenge tests were both $20-52 \%$. In 32 out of the 34 patients, the stainless steel welding challenge test was positive. In two patients, the welding challenge test was suggestive of OA (a delayed drop in PEF value of $17 \%$ in both); thereafter, the challenge tests were continued with grinding dust of stainless steel, with positive findings (a delayed drop in FEV1 value of $29 \%$ in one and of $27 \%$ in the other). Both these patients had also experienced work-related asthma symptoms from grinding dust.

The mode of the asthmatic FEV1/PEF reaction was delayed in $16(47 \%)$, immediate in nine $(27 \%)$, and dual in nine $(27 \%)$ patients. Wheezing was heard in lung auscultation during challenge tests in 16 patients. There were no statistical differences related to the occurrence of the mode of the asthmatic reaction (delayed versus immediate or dual reaction) between patients with serum IgE positivity, SPT reaction

\section{TABLE 2 Lung function examinations of study patients at time of diagnosis of occupational asthma and at follow-up examination} 6 months later

Primary investigations

$16 / 34(47)$

$15 / 34(44)$

$3 / 34$ (9)

$0 / 34(0)$

$11 / 29(38)$

$12 / 29(41)$

$5 / 29(17)$

$1 / 29(4)$
Follow-up examination 6 months later

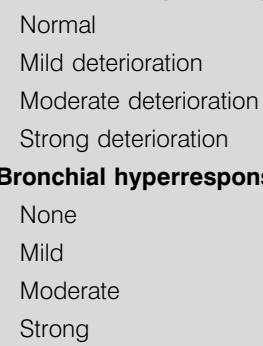

16/33 (48)

14/33 (42)

$3 / 33$ (9)

0/33 (0)

$6 / 15(40)$

$4 / 15$ (27)

$3 / 15(20)$

2/15 (13)

Data are presented as positive/tested (\%) 


\begin{tabular}{|c|c|c|c|}
\hline \multirow{2}{*}{ TABLE 3} & & \multicolumn{2}{|c|}{ Vocational recommendation } \\
\hline & & $\begin{array}{l}\text { At the time of diagnosis of } \\
\text { occupational asthma }\end{array}$ & $\begin{array}{l}\text { At the follow-up examination } \\
\qquad 6 \text { months later }\end{array}$ \\
\hline \multicolumn{2}{|c|}{ Continuation of welding work } & $12(39)$ & $6(19)$ \\
\hline \multicolumn{2}{|c|}{ Discontinuation of welding work } & $19(61)$ & $25(81)$ \\
\hline \multicolumn{2}{|c|}{ Starting of measures of vocational rehabilitation } & $9 / 19(47)$ & $14^{\star} / 25(56)$ \\
\hline \multicolumn{2}{|c|}{ Relocation within the same organisation } & $5 / 19(27)$ & $4 / 25(16)$ \\
\hline \multicolumn{2}{|c|}{ Sick leave } & $3 / 19(16)$ & $0 / 25(0)$ \\
\hline \multicolumn{2}{|c|}{ Occupational injury pension } & $2 / 19(10)$ & $7 / 25(28)$ \\
\hline
\end{tabular}

Data are presented as $n, n(\%)$ or positive/recommended $(\%) . ~ *$ : Transferred to other work tasks $(n=1)$ or retired $(n=2)$ before examinations. ${ }^{\%}$ : Starting or continuing of measures of vocational rehabilitation.

positivity to common environmental allergens, positive family history of asthma or positive history of atopy (data not shown). Furthermore, neither the duration of exposure nor the duration of exposure before the respiratory symptoms differed significantly between these groups (data not shown). Bronchial hyperresponsiveness was measured both before and after the challenge test in four patients, all of whom showed an increased post-exposure reactivity. During the challenge tests, otorhinolaryngological status was observed in 10 patients, but no diagnosis of occupational upper respiratory tract disease was made.

After the diagnosis of OA, all patients started or continued regular asthma medication. Before the examinations at the $\mathrm{FIOH}$, two patients had already retired and one patient's work tasks had changed and no longer included welding (table 3). At the $\mathrm{FIOH}$, the assessment of work ability was based on the description of work tasks, lung function measurements and PEF surveillance (both before and during the examinations). Assuming that exposure to stainless steel welding fumes was minimised, with the use of a motorised respiratory protective device and with optimal asthma medication, it was assessed to be possible that one-third of patients could continue welding work. For the remaining patients, either vocational rehabilitation, relocation within the same organisation, occupational injury pension or sick leave was recommended.

A total of 33 patients participated in the follow-up examination at the FIOH 6 months after the diagnosis. Spirometry was normal in 16 patients, but showed mild obstruction in 14 and moderate obstruction in three patients (table 2). Histamine challenge tests were performed on 15 patients, showing no bronchial hyperresponsiveness in six, mild in four, moderate in three and strong hyperresponsiveness in two patients.

In the follow-up examination, earlier asthma medication was continued in all patients, with slight modification if required. The recommendations of vocational rehabilitations are shown in table 3. Continuation in welding work was assessed to be possible for six welders only. No serum $\operatorname{IgE}$ positivity or significant differences related to age, duration of exposure, duration of respiratory symptoms or mode of the asthmatic reaction were found between those who could continue and those who could not (data not shown).

\section{DISCUSSION}

The present study describes clinically examined patients with OA diagnosed by positive stainless steel welding challenge tests. The diagnosis of OA was based on a history of exposure, respiratory symptoms and clinical examinations including positive challenge tests. During the 10 -yr period of the present study, $34 \mathrm{OA}$ cases were diagnosed at the $\mathrm{FIOH}$, which gives an occurrence of OA of 3.4 cases per year. It is estimated that there are 13,000 full-time welders in Finland; however, it is difficult to describe how many of these perform only or mainly welding on stainless steel. One crude estimate is 2,000-4,000, which is based on the Register of Workers at Risk of Being Exposed to Carcinogenic Substances and Processes (the register is maintained at the FIOH). All employers must report workers who are exposed significantly to carcinogens to this register; the carcinogens concerning welding are hexavalent chromium and nickel. When using this estimate for the number of stainless steel welders in Finland, this gives an incidence of OA 0.0009-0.002 per worker per yr.

The mean duration of exposure to welding fumes before the onset of the respiratory symptoms was long: 18 yrs. This time refers to the duration of the occupation rather than to the actual exposure time. Although all the present patients were exposed to stainless steel welding fumes, it was impossible to estimate the true amount of this exposure because the information was based on patient interviews without measurements being taken at the working sites. A similar duration has been reported earlier in case studies of stainless steel welding $[3,5]$, but shorter intervals have also been described in stainless steel welding case studies or welding of other materials $[6,7,19]$. The observed differences between studies could be explained by the intensity of exposure to welding fumes, welding methods and materials, common ventilation of the welding area and the use of a personal respiratory protective device.

The diagnosis of OA was generally made within 4 yrs of the onset of respiratory symptoms, although in individual cases 
the respiratory symptoms had clearly lasted longer. In the latter cases, the diagnosis may have been delayed by a lack of awareness of this disease among healthcare professionals or because of reluctance on the part of the patients to admit workrelated symptoms. In published case reports, the interval between the onset of respiratory symptoms and the diagnosis of OA has ranged from an immediate occurrence up to 8 yrs $[3,5-7,19]$.

Besides work-related respiratory symptoms, nasal or laryngeal symptoms were also common. These have been described previously among welders $[2,20]$. Although nearly two-thirds of the present patients reported such symptoms, no diagnosis of occupational upper respiratory tract disease was made based on the otorhinolaryngological findings observed during the challenge tests. This is compatible with previous studies: to the present authors' knowledge, no cases of challenge testpositive occupational rhinitis associated with welding fumes have been published, although such a case has been described dealing with occupational laryngitis [21].

None of the patients in the present series showed positive allergic reactions to tested metal salts in SPT. This test negativity is in accordance with previous studies in which these tests have been performed $[4,5,7]$. In contrast, a recent study showed that nearly $12 \%$ of welders had at least one positive SPT to a metallic salt solution (aluminium, cadmium, chromium, copper, iron, manganese, nickel or zinc) [22]. However, skin sensitisation was not significantly associated with symptoms of welding-related asthma [22].

The fumes generated during mild steel welding contain mainly iron (80-95\%) and also manganese (1-15\%), whereas stainless steel welding produces a smaller amount of these but high amounts of chromium (15-30\%) and nickel (5-10\%) [1]. Mild steel welding was used as a control challenge test because mild steel welding fumes consist mostly of iron, which is considered to be inert [1]. Another reason to use mild steel welding as a control challenge test was that the placebo challenge test procedure should be as similar as possible to the active one.

The underlying mechanisms associated with OA related to stainless steel welding are unsettled. It has been proposed that exposure to chromium and/or nickel through stainless steel welding has an aetiological role [3]. An IgE-mediated mechanism has been suggested in some studies, although skin reactivity to metal salts has not been consistently demonstrated in subjects with OA caused by these agents [23]. As mentioned above, none of the present patients showed positive allergic reactions to tested metal salts in SPT in the present study. However, a negative SPT reaction does not automatically exclude IgE mediation. In general, the challenge test reaction is usually positive immediately if the pathophysiological mechanism is IgE-mediated [24]. In the present series, the FEV1/PEF reaction was immediate (or dual) and delayed in $\sim 50 \%$ of the cases. Therefore, although the present study was not aimed at elucidating the pathophysiology of OA in welders, the results reveal that besides a possible IgE-mediated mechanism, other immunological mechanisms may also exist.

The outcome of OA has not previously been addressed in welders. According to the present series, the short-term prognosis of OA was poor: the continuation of welding work was assessed to be possible only in a minority of patients. In the majority of patients, measures of vocational rehabilitation had to be undertaken, or occupational injury pension was recommended. Of the studied variables, age, duration of exposure, duration of respiratory symptoms, mode of the asthmatic reaction or serum IgE positivity did not influence the short-term prognosis. The present findings emphasise the importance of further studies to assess the factors contributing to the long-term prognosis of OA among welders.

In conclusion, the duration of exposure time in developing occupational asthma was often long. After the diagnosis of occupational asthma, the continuation of welding work was impossible in most cases. The possibility of occupational asthma should be recognised not only by occupational physicians working among welders but also by pulmonologists examining patients with work-related respiratory symptoms.

\section{ACKNOWLEDGEMENTS}

The authors would like to thank T. Suomela for secretarial help.

\section{REFERENCES}

1 Antonini JM, Lewis AB, Roberts JR, Whaley DA. Pulmonary effects of welding fumes: review of worker and experimental animal studies. Am J Ind Med 2003; 43: 350-360.

2 Sjögren B. Effects of gases and particles in welding and soldering. In: Zenz C, Dickerson OB, Horvath EP, eds. Occupational Medicine. St Louis, Mosby Year Book Inc, 1994; pp. 917-925.

3 Keskinen H, Kalliomäki P-L, Alanko K. Occupational asthma due to stainless steel welding fumes. Clin Allergy 1980; 10: 151-159.

4 Contreras GR, Chan-Yeung M. Bronchial reactions to exposure to welding fumes. Occup Environ Med 1997; 54: 836-839.

5 Hannu T, Piipari R, Kasurinen H, Keskinen H, Tuppurainen M, Tuomi T. Occupational asthma due to manual metal-arc welding of special stainless steels. Eur Respir J 2005; 26: 736-739.

6 Keskinen H, Pfäffli P, Pelttari M, et al. Chlorendic anhydride allergy. Allergy 2000; 55: 98-99.

7 Vandenplas O, Delwiche J-P, Vanbilsen M-L, Joly J, Roosels D. Occupational asthma caused by aluminium welding. Eur Respir J 1998; 11: 1182-1184.

8 Karjalainen A, Kurppa K, Martikainen R, Karjalainen J, Klaukka T. Exploration of asthma risk by occupation extended analysis of an incidence study of the Finnish population. Scand J Work Environ Health 2002; 28: 49-57.

9 Kogevinas M, Anto JM, Soriano JB, Tobias A, Burney P. Occupational asthma in Europe and other industrialised areas: a population-based study. Lancet 1999; 353: 1750-1754.

10 Wang ZP, Larsson K, Malmberg P, Sjögren B, Hallberg BO, Wrangskog K. Asthma, lung function, and bronchial responsiveness in welders. Am J Ind Med 1994; 26: 741-754.

11 Beach JR, Dennis JH, Avery AJ, et al. An epidemiologic investigation of asthma in welders. Am J Respir Crit Care Med 1996; 154: 1394-1400. 
12 Torén K, Järvholm B, Brisman J, Hagberg S, Hermansson B-A, Lillienberg L. Adult-onset asthma and occupational exposures. Scand J Work Environ Health 1999; 25: 430-435.

13 Kanerva L, Estlander T, Jolanki T. Skin testing for immediate hypersensitivity in occupational allergology. In: Menne T, Maibach HI, eds. Exogenous Dermatoses: Environmental Dermatitis. Boca Raton, CRC Press, 1991; pp. 103-126.

14 Viljanen AA. Reference values for spirometric, pulmonary diffusing capacity and body plethysmographic studies. Scand J Clin Invest 1982; 42: Suppl. 159, 1-50.

15 Quanjer PH, Tammeling GJ, Cotes JE, Pedersen OF, Peslin R, Yernault J-C. Lung volumes and forced ventilatory flows. Eur Respir J 1993; 6: Suppl. 16, 5-40.

16 Sovijärvi ARA, Malmberg LP, Reinikainen K, Rytilä P, Poppius H. A rapid dosimetric method with controlled tidal breathing for histamine challenge. Repeatability and distribution of bronchial reactivity in a clinical material. Chest 1993; 104: 164-170.

17 Burge PS. Single and serial measurements of lung function in the diagnosis of occupational asthma. Eur J Respir Dis 1982; 63: Suppl. 123, 47-59.
18 Allergy Practice Forum, Guidelines for the diagnosis of occupational asthma. Clin Exp Allergy 1992; 22: 103-108.

19 Lee HS, Chia SE, Yap JCH, Wang YT, Lee CS. Occupational asthma due to spot-welding. Singapore Med J 1990; 31: 506-508.

20 Meo SA, Al-Khlaiwi T. Health hazards of welding fumes. Saudi Med J 2003; 24: 1176-1182.

21 Hannu T, Piipari R, Toskala E. Immediate hypersensitivity type of occupational laryngitis in a welder exposed to welding fumes of stainless steel. Am J Ind Med 2006; 49: 402-405.

22 El-Zein M, Infante-Rivard C, Malo J-L, Gautrin D. Is metal fume fever a determinant of welding related respiratory symptoms and/or increased bronchial responsiveness? A longitudinal study. Occup Environ Med 2005; 62: 688-694.

23 Bernstein IL, Nemery B, Brooks S. Metals. In: Bernstein IL, Chan-Yeung M, Malo J-L, Bernstein DI, eds. Asthma in the Workplace. New York, Marcel Dekker, Inc, 1999; pp. 501-521.

24 Chan-Yeung M, Malo J-L. Occupational asthma. N Engl J Med 1995; 333: 107-112. 